\title{
CONTRIBUIÇÕES DA SOCIOLOGIA DAS CONSTITUIÇÕES PARA A ANÁLISE DA PARADOXALIDADE DO DIREITO À SAÚDE
}

\section{${ }^{1}$ Sandra Regina Martini}

\section{RESUMO}

O presente artigo expõe as contribuições da Sociologia das Constituições para a análise das paradoxalidades da construção do Sistema da Política e do Sistema do Direito e do direito à saúde no contexto de um Direito Cosmopolita. A Constituição consagrou simbolicamente determinados valores - como a saúde - em seu texto, tornando-os direitos exigíveis. Entretanto, na atual sociedade complexa, os direitos devem sair do plano simbólico e passar para o plano real. No artigo, sustenta-se teoricamente um sistema social da saúde diferenciado funcionalmente, capaz de absorver as demandas e reduzir complexidades.

Palavras-chave: Constituição, Sistemas sociais, Direito à saúde, Teoria sistêmica

\section{CONTRIBUCIONES DE LA SOCIOLOGÍA DE LAS CONSTITUCIONES PARA EL ANÁLISIS DE LAS PARADOJAS DEL DERECHO A LA SALUD}

\section{RESUMEN}

El artículo expone las contribuciones de la Sociología de las Constituciones para el análisis de las paradojas de la construcción del Sistema de la Política y del Sistema del Derecho y del derecho a la salud en el contexto de un Derecho Cosmopolita. La Constitución consagró simbólicamente determinados valores como la salud en su texto, haciéndolos derechos. Sin embargo, en la sociedad compleja, los derechos deben salir del plano simbólico y pasar al plano de lo real. El artículo analiza teóricamente un sistema social de la salud diferenciado funcionalmente, capaz de absorber las demandas sociales y reducir complejidades.

Palabras-claves: Contitución, Sistemas sociales, Derecho a la salud, Teoría sistémica

\footnotetext{
1 Pós-Doutorado em Políticas Públicas pela Universidade de Salerno - US, Itália. Professora titular da Universidade do Vale do Rio dos Sinos - UNISINOS, Rio Grande do Sul, Brasil. E-mail: srmvial@terra.com.br
} 


\section{INTRODUÇÃO}

“A Constituição é a Forma pela qual o Sistema Jurídico Reage à Própria Autonomia." (LUHMANN, 1990, p.183) ${ }^{1}$

Reagir à própria autonomia significa definir os limites e as possibilidades do operar de cada sistema social. É por meio dessa autonomia que a Constituição coloca constantemente em contato o sistema da política e o sistema do direito, mostrando que ela tem um importante papel na mudança do direito, porém se esta mudança somente se dará nos limites do próprio direito, o mesmo vale para o sistema da política, bem como para todos os demais sistemas sociais.

Os termos "reação" e "autonomia" mostram os limites/possibilidades de cada sistema, mas destacam sobretudo os problemas estruturais do próprio sistema, por exemplo, continuamos - e paradoxalmente necessitamos - entendendo o Direito a partir do pressuposto do Estado-Nação, ou seja, temos como referência principal para o Direito uma clara delimitação geográfica, uma ideia de soberania; já quando observamos o sistema da política ou da economia vemos que seus pressupostos estão muito mais vinculados a ideia de sociedade mundial. Estas limitações podem também se transformar em possibilidade. Este é o jogo da ambivalência do viver em uma sociedade diferenciada funcionalmente, onde temos como possibilidade também a aproximação entre os sistemas sociais desde a abertura cognitiva.

Para a análise, o artigo será dividido em seis partes. Na primeira parte, abordaremos a ambivalência das constituições atuais; na segunda a (im)possibilidade da sociologia das constituições. Na terceira a constituição como um valor; na quarta a saúde desde a perspectiva valorativa até a constitucionalização. Na quinta a relação da saúde com o futuro e o risco no sistema da saúde. E na sexta e última parte faz-se, necessário, diante das pesquisas e discussões acerca da saúde como sistema, abordar a caracterização do sistema da saúde como sistema social.

\section{AMBIVALÊNCIAS DAS CONSTITUIÇÕES}

A forma limites/possibilidades pode ser muito oportuna para a análise da evolução da atual sociedade, pois operamos sempre superando limites e então criando possibilidades. Assim, dadas as possibilidades, ao mesmo tempo criamos novos

1 Tradução livre. Conferir, ainda, o texto A constitucionalização simbólica, de Marcelo Neves. (NEVES, 2007, p.156). 
limites, que mais uma vez podem e apresentam possibilidades. Este é o funcionamento atual dos sistemas sociais, em que a Constituição apresenta-se como relevante para ambos os lados da forma limite/possibilidade. O fato é que temos falado muito nesta forma, mas utilizado pouco como instrumento de análise. A proposta deste artigo é também explorar esta forma de análise, pois ela nos permite desvelar constantemente os paradoxos da inclusão universal, por exemplo. Entendo, com Eligio Resta, que o limite pode também apresentar outro significado, ao tratar da questão da identidade:

O limite, dizia-se, define, individua; mas ao mesmo também uma proveniência. Apresenta-se sob forma de oximoro, de uma individuação que não esquece sua origem na qual a individuação se confunde. Entre a nova identidade e a sua diferença o ligame que separa é o mesmo que une: aquilo que as define é também aquilo que as aproxima.(RESTA, 2014, p. 102)

Utilizamos este conceito para tratar da Constituição como uma identidade moderna, que joga muitas vezes um duplo jogo, ou como afirma Resta "joga com a cumplicidade dos seus opostos"; outras vezes a pode identificar, no limite, uma proveniência, porém a ambivalência está sempre presente: o mesmo ligame que une pode separar. Exemplificando, podemos falar do papel que Constituição paraguaia “jogou” em 2013? Quando ocorreu o "golpe político" no Paraguai, ou seja, uma Constituição criada para garantir a democracia pode garantir (e garantiu) o seu oposto, pois não podemos dizer que o processo de impeachment foi democrático, pois em $18 \mathrm{~h}$ se cumpriu todo o processo. Esta situação nos faz pensar em qual a identidade constitucional que prevalece, a democrática ou aquela das velhas "castas políticas". Não aprofundaremos a discussão deste exemplo, porém ele nos mostra como funciona o jogo do limite/possibilidade. Para Emilio Camacho,

El golpe parlamentario perpetrado em Paraguay constituye un golpe a la democracia latinoamericana y es atentatorio contra los princípios universales de la democracia, una ameaza directa a la región protagonizada por los sectores más conservadores y antidemocráticos de la sociedad, que puede extenderse a outros países de frágil institucionalidad (CAMACHO, 2012, p. 27)

Novamente vemos que está limitação imposta pode se transformar em possibilidades, pois um fato ocorrido em um determinado Estado impacta em todos os demais. Foi o que ocorreu a partir deste episódio, onde desvelou-se o duplo jogo que a própria Constituição pode representar. Acredito que este Golpe demarca, na América 
Latina, as fragilidades das nossas democracias e desvela o papel das Constituições como autoaplicáveis.

Assim, falar na contemporaneidade, de constitucionalização, dos direitos é também falar da paradoxalidade que envolve esta era de "constitucionalização universal"; é preciso identificar como todos seremos - se seremos - incluídos universalmente: se isto de fato é possível e quais as limitações que impedem este avanço ou se estamos tratando de algo muito mais valorativo, moralmente correto, mas sem possibilidade de realização. Constitucionalizar direitos não basta! É preciso um programa organizativo para que estes direitos saiam do plano simbólico para o plano real. Precisamos tratar de direitos e não de valores, em se tratando de sistema social.

As reflexões a respeito de outro modelo de Direito sempre estiveram presentes no debate jusfilosófico. Kant, por exemplo, nos fala de um Direito Cosmopolita, onde a ideia racional de uma "comunidade pacífica perpétua" não está efetivada, mais do que isso, ele afirma que a possibilidade de viver todos juntos em harmonia não pode ser vista como um princípio filantrópico, mas como um princípio jurídico. Já que: “a natureza fechou todos os povos juntos"(KANT, 2005, p. 38).

Kant observa os limites de viver num mesmo solo, originariamente em comunhão, não a mesma situação na perspectiva jurídica da posse deste mesmo solo, porém é possível pensar em uma relação de cada um com todos, sem que, assinala Kant, o estrangeiro possa ser visto como inimigo, pois assim o direito poderia permitir uma associação com todos os povos em conformidade com leis universais (as quais na atualidade, não nos faltam), este direito pode ser chamado de cosmopolita. Os mares que poderiam ser outro limite para este direito se apresentam também e ao mesmo tempo como possibilidades através dos mecanismos modernos de navegação.

Estas reflexões atuais de Kant são importantes partindo do seu próprio pressuposto onde a paz é o único estado no qual o meu e o teu são garantidos pela lei, onde os "vizinhos" podem estar reunidos por uma Constituição, na qual o poder está na lei e não nos homens. Esta Constituição deve ser implementada de modo gradual segundo firmes e fortes princípios, em um contínuo processo de chegar a paz perpétua. Os limites para esta paz estão colocados, assim como suas possibilidades.

\section{E A SOCIOLOGIA DAS CONSTITUIÇÕES É POSSÍVEL?}

Ver como a Teoria dos Sistemas Sociais pode contribuir para a análise deste fato. Para tal é necessário retornar aos questionamentos de Niklas Luhmann sobre a 
própria sociologia, para depois ver se efetivamente podemos falar de uma sociologia das constituições ou se estamos falando de uma análise sociológico-sistêmica das constituições. Em especial, devemos considerar as seguintes perguntas, apontadas por Luhmann: “do que se trata o caso? e o que se esconde por detrás?”(LUHMANN, 1996, p.341). Estas perguntas, respondidas a partir da ótica da Teoria dos Sistemas Sociais, nos remetem não a respostas, mas a outras perguntas. Inicialmente é fundamental pensar que quem observa indica, seleciona estabelece diferenças. Neste processo - complexo - , não se pode pensar na separação sujeito objeto, ou seja, tratar o caso e ver o que está por detrás significa ver o que esta por detrás de quem observa o que observa e mais do que isso,

(...)Osservare significa semplicemente (e cosí utilizzaremo in seguito sempre il concetto): distinguire e indicare.(LUHMANN, 1996c,p.23)

$\mathrm{Na}$ medida em que, esta teoria busca desvelar paradoxos e não simplesmente "identifica-los como problema social" ou, talvez até pior, "resolver os problemas sociais", causa dúvidas e desassossegos. Aqui podemos questionar: qual é mesmo a função da ciência? Qual mesmo a função da sociologia? E, sobre isso, destaca Luhmann:

Como ciência, a sociologia só pode estabelecer-se sobre a base da comunicação, referindo suas contribuições unicamente à descrição interna desse sistema, e sem tomar nenhuma posição externa, pois isto significaria não poder expressá-lo (LUHMANN, 1996a, p.341).

Partindo desta afirmação vemos que a sociologia também vem se estabelecendo. Assim, a ideia de Sociologia da Constituição, nasce com o pensamento de Alberto Febbrajo e Giancarlo Corsi, os quais observam que o papel que as Constituições vêm sendo na sociedade moderna utilizadas teoricamente para permitir o estudo da "relação" entre direito e política.

Esta é uma relação muito complexa, na medida em que a política, na sociedade atual se apresenta como um sistema mundial, enquanto que o direito continua sendo local/nacional. Em outros termos, a política é segmentada, mas a sociedade é mundial, mas continuamos com as limitações territoriais. Por exemplo, não temos uma constituição mundial.

As teorias ou as ciências, de modo geral, produzem efeitos diversos nos estudiosos. A Sociologia em particular parte, tradicionalmente, conforme Luhmann, 
das mencionadas duas questões (abordadas na sua última aula da cátedra em Bielefeld). A primeira é: do que se trata o caso? Em seguida, a pergunta é: o que se esconde por detrás? Estas indagações levaram as reflexões sobre unidade da diferença, ou seja, sobre um paradoxo.(LUHMANN, 1996a, p.361)Então, a sociologia descreve a sociedade como um sistema que se autodescreve. Mas, ao concluir a referida lição Luhmann, observa:

(...) teríamos, então, uma sociedade que, com o auxílio da sociologia, poderia descrever a si mesma. E o que estaria por detrás? Absolutamente nada...(LUHMANN, 1996a, p. 369)

A Teoria dos Sistemas Sociais de Niklas Luhmann "revoluciona" a tradição sociológica, tem um efeito (até hoje) desassossegador: esta teoria se apresenta com vários diferenciais, pois, além de desacomodar qualquer pesquisador, também, e ao mesmo tempo, apresenta-se como um desafio para a análise da complexidade social, uma vez que não aceita as teorias tradicionais na sua íntegra, mas as utiliza para mostrar as fragilidades internas da própria teoria. Além disso, toda a base de construção da teoria é transdisciplinar e construtivista; isso, por um lado, facilita o processo de compreensão da sociedade atual; por outro, não "admite" análises lineares, ou seja, cada análise pode ser diferente da que foi formulada.

Continuamente repetimos os questionamentos de Luhmann, especialmente a pergunta "que direito tem o direito a dizer o que é direito?", e como este direito reage a própria autonomia, estes questionamentos vêm sendo refletido por sociólogos, juristas, filósofos, entre outros... as respostas sempre partem para novos questionamentos. No caso específico da Sociologia, enfrentar este questionamento é “desmontar e montar" as teorias tradicionais da própria sociologia. Até os anos 60 a Sociologia, com raras exceções, não tinha no seu "objeto" de estudo o "dizer e decidir o direito". Especialmente na América Latina, nosso "objeto" de estudo e preocupações estava em outros campos. O problema do "direito a dizer o que é direito", ingressa no mundo da sociologia no Brasil somente após este período através dos vários movimentos de crítica ao direito, a marca inicial desta discussão está em algumas obras entre elas as de Claudio Souto. Direito e Sociologia eram mundos separados, e por isso, possíveis de serem aproximados.

\section{CONSTITUIÇÃO: UM VALOR? MAS QUAL VALOR?}

Uma teoria da sociedade moderna deve estar conceitualmente construída, de modo a que todos os conceitos sejam novamente formulados, caso se queira empregar uma teoria dessa natureza.(LUHMANN, 1996a, p.369) 
A ideia de uma sociologia das Constituições nasce com o pensamento de Alberto Febbrajo, Giancarlo Corsi, Leonel Severo Rocha, Germano Schwartz, entre outros. Seguindo exatamente a observação de Luhmann, os autores formulam novamente os conceitos. Ambos, sabiamente, observam o papel que as Constituições vêm tendo na sociedade moderna. Com as ferramentas da Teoria dos Sistemas Sociais, identificam a possibilidade de uma linha específica de pesquisa. Reafirmando a Teoria Sistêmica, Febbrajo e Corsi, mostram que a Constituição foi inventada para permitir a "relação" entre direito e política no contexto da modernidade. A limitação entre política e direito está dada na Constituição e o simbolismo da Constituição também é questionada por Febbrajo e Corsi, criando muitas vezes uma desordem no direito, a qual não é negativa ou positiva, mas pode apresentar uma solução ou até desvelar a "fragmentação" do direito atual, ou seja, o direito (des)ordenado pode encontrar soluções organizativas. E a Constituição segue como identidade de um Estado, a mudança de sua essência é muito difícil e complexa. Assim, temos continuamente mudança nas normas jurídicas e o que limita estas mudanças é a própria Constituição. Febbrajo diz mais: adverte sobre a importância também do sistema econômico, ou seja, além de considerar a constituição como acoplamento estrutural entre direito e política, também acrescenta o sistema econômico.

Entendendo que a Constituição, conforme Luhmann, é uma aquisição evolutiva (SCHWARTZ; PRIBÁN; ROCHA, 2015), o qual serve como ponto de partida para reflexão da Constituição para além dos valores. Luhmann, conceitua a Constituição como "uma reação à diferenciação entre política e direito, ou dito com ênfase ainda maior, à total separação de ambos os sistemas de funções e à consequente necessidade de religação entre eles”(LUHMANN, 1996b, p.04). Para Luhmann, o direito e a política estão "livres" para ignorar as opiniões científicas que lhes dizem respeito, e é esta liberdade que uma sociologia das constituições poderá desenvolver.

A Sociologia, de modo geral e tradicional, não tem refletido sobre o tema, muito embora deva se ocupar das improbabilidades das estruturas sociais, pouco dedicou ao tema específico. Porém, nos dias atuais tem chamado a atenção também dos sociólogos, especialmente pelo caráter "divino", que as Constituições representam.

Ao mesmo tempo, as Constituições assumem um papel importante. $\mathrm{Na}$ Europa, embora não se "fale" da Constituição, todos sabem da sua existência, e sabe- 
se que serve como limite (como afirma Febbrajo); na América Latina a situação é mais complexa: a Constituição continua sendo "constituída de valores", isto é, fruto dos processos vivenciados por aqui. Onde, diferente dos países Europeus, as Constituições foram e são a marca da passagem de regimes autoritários para regimes democráticos (mesmo que possamos questionar o nível de democracia, ou quanto é democrática a democracia, só podemos fazer porque, de certo modo, existe um nível, ainda que mínimo de democracia). Por isso, no continente latino-americano é urgente uma reflexão sociológica profunda deste tema, já que tradicionalmente quando se estuda o tema o foco tem sido: função, legitimação, fundamento da Constituição, ou traduzindo para termos práticos, em muitos casos, seguimos tratando da "sacralidade" da Constituição. Porém, cremos que uma Sociologia das Constituições poderia aprofundar, sobretudo o lugar das organizações e da estrutura social para a efetivação da Constituição. No Brasil, temos muitos estudos sobre o tema da Constituição, grande parte realizado com o referencial do direito, porém parece urgente rever o tema com o foco da Sociologia.

Como afirma Corsi:

Per questo è opportuno vedere la specificità della sociologia nel fatto che, a differenza delle teorie del diritto o della politologia, non ha il compito di dare indicazioni operative ai giudici o all'azione politica. In ultima istanza, la teoria del diritto è pur sempre e solo parte del sistema del diritto e lì trova il proprio senso, così come la politologia è sempre e solo parte del sistema della politica. Si tratta quindi di un problema di differenziazione della società, che comporta funzioni distinte per i diversi sottosistemi e quindi anche problemi, concetti e costruzioni teoriche differenti. Sul piano della ricerca si può dunque sottolineare la interdisciplinarità o "transdisciplinarità", che presuppone la diversità di prospettive, e lo studio della costituzione è un caso piuttosto chiaro di ricerca che coinvolge prospettive diverse. $^{2}$

Uma sociologia da Constituição não pode ser ideológica, nem operar do mesmo modo que a Ciência Política ou o Direito. A Sociologia da Constituição deve ter presente que a Constituição se autolegitima e fala de si mesma e da possibilidade do seu próprio fim. Na perspectiva desta nova área do conhecimento, a Constituição deve ser "desvelada" de seus valores, sacralidade e ideais. Como fazer isso? Como não repetir as questões iniciais da Sociologia, e chegar a resposta dada por Luhmann? Quando diz que por detrás nada existe!!! 
Como observava Luhmann, a Constituição deve dar limites ao direito e a política, pois deste modo, tanto direito como política podem dar fundamentos para a ausência de fundamentos. Ou seja, a Constituição tem um caráter altamente paradoxal: assim como limita direito e política, também prevê o poder de acabar com ela mesma. Este é o paradoxo e, como paradoxo, entendemos que se criam quando as condições de suas possibilidades também são as condições de suas impossibilidades.

\section{SAÚDE: DO VALOR À CONSTITUCIONALIZAÇÃO}

Quando a saúde passa a ser constitucionalizada reforça a ideia de valor? Ou podemos pensar em um direito? É possível partir de um valor e chegar a um direito? Qual o limite deste direito? Quais os vínculos com o futuro que este direito-valor ou valor-direito pode significar? É possível concretizar um valor?

A saúde tem sido discutida e definida segundo vários parâmetros, nos mais variados períodos históricos. Muito embora a definição moderna abarque a integralidade do viver em sociedade, vemos que esta ainda aparece como um valor, claro que um dos valores mais afirmados e visíveis no panorama simbólico da sociedade moderna. Não é estranho, que seja assim, já que qualquer outro valor pressupõe que os indivíduos esteja aptos para gozar o próprio bem estar corporal e mental, se não temos saúde para tal, os demais valores se tornam inexequíveis. A doença, especialmente se for grave, ataca a possiblidade da liberdade ou da igualdade do indivíduo e pode inclusive colocar em discussão a própria dignidade.

2 Conferência realizada no Minicurso Teoria dos Sistemas e Direito, realizada no Programa de Pós-Graduação em Direito da Universidade do Vale do Rio dos Sinos, em novembro de 2014. 
Com a evolução da sociedade atual, observamos que alguns valores podem se tornar direito ou talvez esta seja a expectativa latente na América Latina. E aqui novas complexidades surgem: se a saúde é um valor e, como tal deve ser garantido para todos a tal ponto que aparece em grande parte das Constituições modernas, temos que ter programas e estruturas que permitam a transposição de um valor em um direito, ou seja, uma vez estabelecido que a saúde é um direito inalienável, devem existir condições para que este direito seja garantido. O problema é como e onde estabelecer os critérios para que o sistema da saúde e do direito possam operar, ou melhor, como este direito possa ser decidido na estrutura do sistema da saúde. De fronte a esta situação temos que considerar também o sistema da política, que do seu ponto de vista vê a afirmação, também constitucional, dos direitos com um ponto "indiscutível”, sem preocupar-se das consequências deste direito. Saúde para todos, assim como trabalho para todos ou igualdade de oportunidades, são clássicas lutas sociais. O problema (e a solução) está exatamente nestes "todos", pois todos se distinguem de "nenhum”, pois estamos diante do risco que nenhum ou somente poucos possam verdadeiramente usufruir destes direitos. Porém, a política se é democrática, não pode decidir senão pensando em todos, a qualquer custo.

Falar na saúde como direito, ou melhor, de um valor para um direito, significa também pensar seriamente sobre a questão da exclusão social. Ou melhor, ter presente que nesta sociedade onde há muita inclusão, esta muitas vezes se dá através da exclusão, sendo assim, a saúde continua sendo "pensada, organizada e planejada" como valor. Hoje, falamos de doenças da civilização, epidemias que se alastram sem controle, novas doenças (por exemplo: hoje a violência é considerada um problema de saúde), catástrofes ambientais, entre outros. Podemos ver que a garantia de uma saúde de qualidade passa por uma inclusão generalizada.

A função de uma "sociologia das Constituições" poderia ser, no caso da saúde, colocar em destaque as condições socioculturais que permitem esta inclusão universal (se permitem) e os obstáculos desta passagem da saúde como valor para a saúde como direito. Sobre este tema Giancarlo Corsi observa:

$\mathrm{Ci}$ si dovrebbe chiedere, in altre parole, come è possibile attivare e sostenere la cura delle malattie ponendo come punto di riferimento il valore della salute. Proprio se si prende sul serio tale valore, l'impressione è che tutta la realtà sociale venga messa in discussione dal punto di vista della malattia e che questo si ripercuota non solo sulla medicina (per la quale ciò è del tutto normale e ovvio), ma anche su altri sottosistemi della società $^{3}$. 
Entender a paradoxalidade do valor ou do direito à saúde, implica necessariamente, ver quais as implicações da prevenção e da cura de uma determinada doença. Aqui entramos em outro campo: a dimensão social e ética da doença. Sem entrar em detalhes sobre estas dimensões, apenas as nominamos pois refletem a complexidade que tema gera. Mais do que isso, desde uma perspectiva da Sociologia das Constituições podemos refletir: se assumindo a dimensão social e ética da doença não estamos aumentando o valor? Não estamos nos distanciando da efetivação de condições mínimas de saúde? Como os sistemas sociais vão operar com um complexo valor?

Assim vemos que as perspectivas dos mais diversos sistemas sociais são divergentes, basta pensar na perspectiva do sistema da religião, por exemplo. Se pensarmos no sistema da educação e sua relação com a saúde. De que modo a informação pode transformar o valor em direito?

\section{SAÚDE: FUTURO E RISCO DO SISTEMA DA SAÚDE: DE ONDE VEIO E PARA ONDE VAI}

Questões complexas aparecem quando se trata de decidir sobre tecnologia genética e sobre as novidades tecnológicas. Trata-se de ver como a técnica opera, se opera e quando e como opera. Importante saber se a técnica opera também como remédio/veneno, por isso a complexidade do tema. Relacionado a isto temos a preocupação com a "segurança", com as certezas...quando se trata de novas tecnologias vemos que estas muitas vezes vem como propulsoras do progresso e do desenvolvimento. Assim, de modo geral, ser contra as novas tecnologias "é politicamente incorreto" ou também ser politicamente correto quando se fala desde a ótica dos direitos humanos.

Diante dos novos avanços tecnológicos, vemos o dilema da política: permitir novas tecnologias correndo riscos ou proibir. Assim, não se corre o risco dos

3 Conferência realizada no Minicurso Teoria dos Sistemas e Direito, realizada no Programa de Pós-Graduação em Direito da Universidade do Vale do Rio dos Sinos, em novembro de 2014. 
possíveis danos. Não podemos desconsiderar que o sistema da política pode fornecer subsídios importantes para as inovações tecnológicas, em especial da área da saúde.

Vemos que esta discussão, também "interessa" para outros sistemas sociais. O direito, por exemplo, pode criar "problemas", como na determinação jurídica de que determinados tratamentos devem ser realizados e, relacionando-se com o sistema da economia, coloca os limites dos "gastos". Assim, determina os valores dos procedimentos na área de saúde, tema hoje altamente criticado pelos operadores do sistema de saúde, em especial os médicos, estes que por sua vez reagem de várias formas no que diz respeito utilização de terapias muitos vezes de alto custo. A medicina, tem como referência a ciência, ou melhor as inovações. Por isso, ao mesmo tempo que é fonte de possibilidade de tratamento o Estado pode não disponibilizar recursos para tal.

\title{
SAÚDE COMO SISTEMA SOCIAL
}

Claro que a questão da saúde passa a ser também uma questão para os demais sistemas sociais. Nas nossas pesquisas, em que pese todas as dificuldades, entendemos a saúde como um sistema social. Inicialmente, destacamos que Luhmann - assim como seus seguidores - não trabalharam o sistema da saúde, mas sim o sistema da medicina. Para nossas pesquisas, a ideia geral da teoria dos sistemas nos permite abordar a saúde como um sistema social, exatamente em função das observações do próprio autor:

\begin{abstract}
La interdipendenze tra medicina ed altri sistemi di funzioni sono molto importanti. Il sistema della medicina è strutturalmente accoppiato con l' economia, la scienza, Il sistema giuridico e cosi via: la cura medica richiede decisioni politiche, conoscenze scientifiche, finanziamenti, regolazione giuridica. La interdipendenze non intaccano l' autonomia del sistema della medicina: possono essere coinvolti uffici di lavoro, sedute parlamentari, comissioni etiche, preti, parenti, ma la costruzione della malatia rimane matéria della medicina. (CORSI, 1996,p.145) ${ }^{4}$
\end{abstract}

Aqui, temos mais indicativos da possibilidade, independentemente de Luhmann ter abordado a saúde como um sistema social. Além disso, ele aponta para o

“As interdependências entre medicina e outros sistemas de funções são muito importantes. O sistema médico é estruturalmente acoplado com a economia, ciência, o sistema legal e assim por diante: a assistência médica requer decisões políticas, conhecimentos científicos, financiamento, regulamentação legal. As interdependências não afetam a autonomia do sistema da medicina: podem estar envolvidos escritórios de trabalho, sessões parlamentares, comissões de ética, padres, familiares, mas a construção da doença continua a ser uma matéria da medicina.” Tradução livre. 
caráter transdisciplinar e intersetorial da saúde, mesmo afirmando que doença é matéria da medicina. Para os sanitaristas, essa abordagem pode render críticas, porém essa não é nossa preocupação: queremos mostrar que o autor deixa instrumentos suficientes para o entendimento da saúde como um sistema diferenciado funcionalmente. Temos outra passagem interessante que nos leva para este caminho, aquela na qual Luhmann afirma que o sistema médico pode ter também um código secundário:

$\mathrm{Si}$, afferma, invece, la possibilità di un códice secondario, grazie alla tecnologia genética: la distinzione geneticamente perfetto / geneticamente preoccupante permette di determinare una distinzione secondaria curabile / incurabile, riferita alla malattia: la cura dei malati viene poi richiesta su entrambi i lati della distinzione. (CORSI, 1996, p.146) ${ }^{5}$

Luhmann percebeu a complexidade que envolve o sistema da medicina e, com isso, permitiu que novas reflexões que ultrapassem os campos médico, ético e político, sejam produzidas. Isso mostra que, evolutivamente, o campo da medicina vem se ampliando motivado pela inflação das possibilidades de tratamento, bem como pelos custos destes tratamentos.

Ao entendermos a saúde como um sistema também concordamos com a posição luhmaniana de que não existe um sistema mais importante do que o outro, mas cada sistema tem uma função que o diferencia dos demais. Esta postura estará presente em todo o artigo, no qual tentaremos mostrar como opera o sistema da saúde e sua relação com os demais sistemas sociais.

A sociedade como um sistema social é composta por subsistemas, é constituída por comunicação, ou seja, é uma malha de comunicações. Sem comunicação, não é possível fazer nenhuma seleção, escolha. A necessidade de seleção (escolha) decorre justamente do fato de o sistema não conseguir dar conta desse contingente de possibilidades, da complexidade interna. Esse excesso de possibilidades é proporcional à gama de elementos do seu interior, e as relações entre

\footnotetext{
"Se afirma, no entanto, a possibilidade de um código secundário, graças à tecnologia genética: a distinção do geneticamente perfeito/geneticamente preocupante nos conduz a determinar uma distinção secundária curável/incurável, referida a doença: o tratamento e a cura dos pacientes são, então, necessários em ambos os lados da distinção.” Tradução livre.
} 
esses elementos fazem crescer o número de possibilidades. Este crescente número de possibilidades tornam a sociedade altamente complexa, de risco e em permanente evolução.

As possibilidades não realizadas ficam potencializadas como opções para o futuro e de algum modo são absorvidas pelo sistema. O sistema seleciona algumas possibilidades, opções, que estejam em consonância com a função que ele desempenha. É a simplificação da complexidade do ambiente como condição de sobrevivência do sistema, mas isso desencadeia o aumento da complexidade do sistema. O número de possibilidades aumenta internamente, podendo até gerar sua autodiferenciação, resultando em novos subsistemas ${ }^{6}$. O motivo que enseja a sua evolução é a sobrevivência à complexidade, que cria constantemente novas possibilidades. Ou seja, na tentativa de reduzir a complexidade, dá-se o incremento dela.

Diante disso, também podemos afirmar que a saúde se constitui em um sistema social diferenciado funcionalmente. A dificuldade de alguns com esse entendimento está vinculada - pelo menos em alguns casos - ao fato de que Luhmann nunca escreveu nada sobre o sistema da saúde, mas sim sobre o sistema médico. Acreditamos que a teoria ofereça elementos suficientes para afirmarmos que, no processo evolutivo, a saúde foi aprimorando suas comunicações e estruturando-se como um subsistema social, ou em sistema social.

Seguindo a própria definição de sistema social, vemos que a saúde se enquadra perfeitamente bem no conceito de sistema social que, conforme o glossário luhmanniano, "sorgono per autocatalisi dai problemi di doppia contingenza, che permettono di affrontare atraverso le loro operazioni",

Mais ainda, um sistema social precisa diferenciar-se de seu ambiente e ter uma estrutura própria, ser fechado operativamente e aberto cognitivamente. Aliás, somente este fato pode justificar a ideia de irritação entre sistema do direito e sistema da saúde,

6 Para elucidar tal situação, tome-se como exemplo o caso do direito: inicialmente o sistema do direito diferenciou-se em público e privado. Entretanto, dado a sua crescente complexidade, viu-se obrigado a autodiferenciar-se em constitucional, administrativo, penal, comercial, e assim sucessivamente. Esse processo revela a evolução do sistema, que é diferente de desenvolvimento, que é passível de controle, enquanto a evolução não é controlável. Maiores informações ver: LUHMANN, Niklas. Inflazione di pretese nel sistema delle malattie: una presa di posizione dal punto di vista della teoria della società. In: CORSI, Giancarlo. Salute e malattia nella teoria dei sistemi, Milano: FrancoAngeli, 2015.

$7 \quad$ "Surgem por autocatálise dos problemas de dupla contingência, que permitem enfrentar através de suas próprias operações.” 
o que, como já referimos, muitos chamam de judicialização, ou "un sistema sociale, quindi, è un sistema distinto da un ambiente ed operazionalmente chiuso, cio è capace da sé i proprie lementi e le propri estruture"(CORSI, 1996,p.213) ${ }^{8}$

Vemos que, em todas as sociedades, o sistema da saúde foi se diferenciando e se autorreproduzindo em contínua irritação com os demais sistemas sociais, em especial com o sistema do direito - aí falamos em judicialização, e o sistema da política é obrigado a tomar decisões coletivamente vinculantes.

Porém, não podemos desconsiderar as observações de Luhmann sobre o sistema médico, ou melhor, sobre medicina, pois ele afirma que o "sistema da medicina":

Il sistema dela medicina o sistema di cura dei malati è uno dei sistemiparziali per della società differenziata per funzioni. Questo sistema si orienta primariamente all' ambiente dellasoceità, è concentrato sui problemicheosserva in tale ambiente: lacomunicazioni al suo interno non si occupa di se stessa, bensìdellecondizioniorganiche o mentalidegliuomini ${ }^{9}$.

Interessante observar que Luhmann escreveu poucos artigos sobre o sistema médico, nos quais a saúde aparece sempre como parte do código binário saúde/doença, ou melhor: do código são/doente. Alerta Luhmann, no entanto, que os conceitos de são e de doente não indicam um particular estado físico ou psíquico, mas têm o valor de código, no qual o valor positivo é o da doença, e o negativo é o da saúde. Ou seja, o que vai importar para este sistema não é a saúde, mas sim a doença, já que só esta importa para os médicos. Para quem não entende a perspectiva da teoria, isso pode parece absurdo, porém é fundamental destacar o que o autor quer dizer com isso: para os médicos, a questão a ser resolvida é a doença, não a saúde.

Certamente Luhmann se referia às dificuldades de efetivar e dimensionar a própria definição da OMS sobre saúde, bem como as especificidades da saúde em cada comunidade. Outro aspecto relevante é que o valor significativo para o sistema da medicina não é o valor positivo (estar são), mas sim a doença. Em outros termos:

\footnotetext{
"Um sistema social é, então, um sistema separado de um ambiente e fechado operacionalmente, que é capaz por si só de seus próprios elementos e própria estruturação.” Tradução livre.

9 "O sistema da medicina ou sistema de cura dos doentes é um dos sistemas parciais de uma sociedade diferenciada funcionalmente. Este sistema é voltado principalmente ao ambiente da sociedade, com foco nos problemas que se observam em tal ambiente: a comunicação interna não se ocupa de si mesma, mas das condições orgânicas ou mentais dos homens."
} 
I programmidella medicina si produconosoltantonel contesto dellacodificazione sano/malato e, quindi, sono orientatiallamalattia [...]Poichéll suo valore positivo è lamalattia, la medicina non ha neppurecostruito una teoria dellareflessione. L'agire medico deriva dal valore attribuitoallasalute: ma lasalute non creacollegamentinel sistema e, dunque, non c' è nullasucuiriflettere(CORSI, 1996,p.144) ${ }^{10}$.

Com estas observações, podemos ver que Luhmann deixa indicativos para se pensar na saúde como um sistema social, em cujo contexto ele destaca a existência do código binário referido, mas alerta para a constatação de que o valor que "vale" é o positivo, ou seja, a doença: ela é quem faz o sistema "funcionar" e ser funcionalmente diferenciado dos demais sistemas sociais, mas sempre conectado nesta rede de comunicação que é a própria sociedade, como podemos observar:

La interdipendenzetra medicina edaltrisistemi di funzioni sono moltoimportanti. Il sistema della medicina è strutturalmenteaccoppiatocon l' economia, lascienza, Il sistema giuridico e cosi via: la cura medica richiededecisionipolitiche, conoscenzescientifiche, finanziamenti, regolazionegiuridica. La interdipendenze non intaccano l' autonomia del sistema della medicina: possonoesserecoinvoltiuffici di lavoro, seduteparlamentari, comissionietiche, preti, parenti, ma lacostruzionedellamalatiarimane matéria della medicina(CORSI, 1996$, p. 145$)^{11}$

Aqui temos mais indicativos da possibilidade, independentemente de Luhmann ter escrito de a saúde se constituir em sistema social. Além disso, ele aponta para o caráter transdisciplinar e intersetorial da saúde, mesmo afirmando que doença é matéria da medicina. Para os sanitaristas, essa abordagem pode render críticas, porém essa não é nossa preocupação: queremos mostrar que o autor deixa instrumentos suficientes para o entendimento da saúde como um sistema diferenciado funcionalmente. Temos outra passagem interessante que nos leva para este caminho, aquela na qual Luhmann afirma que o sistema médico pode ter também um código secundário:

$\mathrm{Si}$, afferma, invece, lapossibilità di un códice secondario, graziealla tecnologia genética: ladistinzione geneticamente perfetto / geneticamente preoccupantepermette di determinare una distinzionesecondariacurabile / incurabile, riferitaallamalattia: la cura dei

\footnotetext{
10 "Os programas da medicina se produzem apenas no contexto da codificação saudável/doente e, por conseguinte, são orientados para a doença [...] porque o seu valor positivo é a doença, a medicina não tem sequer construído uma teoria da reflexão. $\mathrm{O}$ ato médicoderiva do valor atribuído para a saúde: mas a saúde não cria ligações no sistema e, portanto, não há nada para refletir.” Tradução livre.

${ }_{11}$ "As interdependências entre medicina e outros sistemas de funções são muito importantes. O

sistema médico é estruturalmente acoplado comaeconomia, a ciência, o sistema legal e assim por diante: a assistência médica requer decisões políticas, conhecimentos científicos, financiamento, regulamentação legal. As interdependências não afetam a autonomia dosistema da medicina: podem estar envolvidos escritórios de trabalho, sessões parlamentares, comissões de ética, padres, familiares, mas a construção da doençacontinua a ser uma matéria da medicina." Tradução livre.
} 
malativienepoirichiestasuentrambi i lati delladistinzione (CORSI, 1996,p. $146)^{12}$

$\mathrm{Ou}$ seja, Luhmann percebeu a complexidade que envolve o sistema da medicina e deixa espaços para novas reflexões que ultrapassam os campos médico, ético e político. Com isso, mostra que, evolutivamente, o campo da medicina vem se ampliando, motivado pela inflação das possibilidades de tratamento, bem como pelos seus custos.

Sabe-se que a imutabilidade não é característica dos sistemas, visto que o ambiente é efetivamente complexo, e isso o influencia internamente. Com a saúde, isso não foi diferente, especialmente se pensarmos na diferenciação funcional do direito até chegarmos ao direito à saúde. Deve-se dizer que a diferenciação do sistema não significa decomposição de um todo em partes, mas significa dizer que cada subsistema tem seu próprio entorno. Não existe um agente externo que modifica: é o próprio sistema que, por uma questão de sua sobrevivência no ambiente, realiza essa diferenciação. Justamente em face dessa mutabilidade, ele foi capaz de autoproduzirse e, assim, alcançamos a expectativa jurídica da saúde. Ele foi irritado suficientemente para fazer a sua seleção e, dentro dessa, a seleção da saúde com o intuito de torná-la expectativa jurídica (regra).

A evolução dos sistemas não ocorre de modo isolado, pois ela depende de irritações do ambiente, e essas irritações, levando em consideração a tolerância do sistema, podem fazê-lo mudar suas estruturas, ou seja, produzir a si mesmo. Sistemicamente, é o que se pode denominar de autopoiese ${ }^{13}$. A autopoiese, por sua vez, é responsável pelo aumento constante das possibilidades até que a complexidade atinja um nível extremamente elevado, nível esse não suportado pela estrutura do sistema, levando-o a diferenciar-se.

O direito diferenciou-se, sofreu irritações do ambiente ao ponto de autoproduzir-se no tocante à saúde como direito, visto que, a partir das irritações do ambiente, ele processou-as conforme o seu código (binário) e positivou, reconheceu a saúde como direito. Essas irritações foram oriundas, especialmente, do Movimento Sanitário e de toda a lógica que permeou a mudança de paradigma na saúde: a saúde

\footnotetext{
12 "Se afirma, no entanto, a possibilidade de um código secundário, graças à tecnologia genética: a distinção do geneticamente perfeito/geneticamente preocupante nos conduz a determinar uma distinção secundáriacurável/incurável, referida à doença: o tratamento e a cura dos pacientes são, então, necessários em ambos os lados da distinção."

13 Foi assim denominada pelos biólogos Maturana e Varela. Por ser uma teoria transdisciplinar, Luhmann trabalhou também com biologia, matemática e física.
} 
já não era mais um mero ato caritativo ou assistencial; passa a ser um direito constitucionalizado.

Esses aportes teóricos no tocante à constitucionalização do direito à saúde servem para compreendermos a evolução do sistema do direito. A Constituição de 1988, na qual aparece a positivação do direito à saúde, é fruto de uma malha de comunicações que confluíram para uma finalidade: reconhecer o direito à saúde na via constitucional.

O sistema do direito recebeu diversas irritações, tais como aquelas advindas do Movimento Sanitário, que podem ser observadas nos fatores mencionados no começo da análise constitucional. Com a institucionalização dos direitos fundamentais, em especial o direito à saúde, a Constituição acabou por reconhecer a supercomplexidade, e é a partir disso que a Carta Magna pretendia responder aos anseios (exigências) do ambiente, por intermédio da comunicação produzida para que isso ocorresse. (NEVES, 2007, p.74-75)

Para concretizarmos o avanço propiciado por essa "malha de comunicações", precisamos de um financiamento com bases legais sólidas e definidas, e essa é a discussão atual do financiamento público de saúde.

A construção teórica da saúde como um sistema social, em uma sociedade em permanente transformação, é possível, embora apresente algumas limitações, as quais serão enfrentadas através do paradoxo limite/possibilidade. Ou seja, o limite que temos para as nossas investigações é a não descrição teórica consistente até os dias atuais da saúde como um sistema social, e é exatamente nesta limitação que vemos a possibilidade de entender a saúde como um sistema social autoreferencial e autopoiético, que se diferencia do seu ambiente e que tem uma estrutura própria. É através desta estrutura que, constantemente, ao reduzir a complexidade acabamos por incrementá-la, situação esta típica de sociedades diferenciadas funcionalmente em permanente evolução.

O modo de operar da Teoria dos Sistemas, de forma transdisciplinar, construtivista, nos leva para o caminho da transformação social- com a qual, muito mais do que uma mudança que não altere determinada situação estruturalmente, ou uma reforma em que os reformadores nunca são reformados- optamos por trabalhar com o conceito de transformação, pois este também rompe com a ideia da separação 
sujeito-objeto, uma vez que, ao transformarmos a sociedade, transformamos o ambiente da mesma.

Os conceitos de transformação e mudança social foram amplamente discutidos pelas ciências, mas - como esperado - não temos uma única definição ou consenso. Para alguns, a mudança é vista como avanço, como regresso, como resultado de contradição. Luhmann não adota um ou outro pensamento, mas uma postura que de certa forma compila todas as concepções discutidas, fazendo uma construção nova através de desconstruções de antigas teorias. Luhmann agrega a ideia de mudança organizativa dizendo que esta se refere sempre e exclusivamente às estruturas do sistema, nunca às suas operações. Além disso, refere que este mutamento ${ }^{14}$ é sempre um mutamento observado ${ }^{15}$.

Reações, manifestações provocam transformações no sistema social - é preciso olhar o passado para produzir novas alternativas. Em outros termos, quem decide leva em consideração o passado, a opinião pública, os movimentos de protesto, mas por fim, a decisão não é tomada por nenhum destes elementos; é tomada dentro da estrutura em que está inserida.

O problema é quando a decisão não é tomada dentro das estruturas, ou seja, pelas instituições que a compõem, tornando seus efeitos ainda mais imprevisíveis e, em muitos casos, corrompendo os códigos binários dos sistemas sociais. As estruturas não conduzem a transformações ou a não-transformações ${ }^{16}$, mas estas devem se dar através delas.

Temos também a preocupação com alguns conceitos utilizados de forma "banal" e, muitas vezes, relacionando-os com a teoria sistêmica. É o caso da expressão "judicialização", que reporta a uma série de reflexões: a) o direito à saúde é

14 Que nós traduzimos como transformação.

15 E ilmutamentoorganizzativo è sempre uncambiamentoosservato. [...] Ma ilmutamento non osservato non è mutamento, poichèil sistema non puòreagire ad esso. L'osservazione è necessariaperchéaltrimentiilmutamento non potrebbeessereintrodottonell'autopoiesidel sistema e non avrebbequindialcunaconseguenza." (LUHMANN, 1996a, p.273) A mudança organizativa é sempre uma mudança observada. [...] Mas a mudança não observada não é mudança, porque o sistema não pode reagir a isso. A observação é necessária porquê, de outra forma, a mudança não poderia ser introduzida na autopoiese do sistema e não haveria então nenhuma consequência. Tradução Livre.

mutamentinell'ambientehannoluogosenzacoordinamento; se dovesseroesserecoordinati, ci si dovrebbepreoccupare ad hoc per lecasualitàche ne deriverebbero." (LUHMANN, 1996a, p.273) As mudanças de estrutura no sistema e as mudanças no ambiente têm seu lugar sem que haja uma coordenação; se devessem ser coordenados, deveriam se preocupar ad hoc pela casualidade que dela derivariam. Tradução Livre. 
entendido como direito à assistência sanitária, este é um típico sinal da tendência de inclusão generalizada, do mesmo modo ocorre com o direito à educação, ao voto, etc; b) imposição de atendimento à saúde por parte de um tribunal de maneira discricionária, o que revela um sério problema também para o sistema econômico, pois não existem recursos suficientes para o atendimento pleno da saúde.

Como consequência, os problemas de saúde são tratados pelo direito, fazendo com que a economia "obrigue" a política a intervir. Assim, todos os sistemas se agitam (se irritam, autoreproduzem, geram mais diferenças, em síntese: evoluem, o que não significa negativo ou positivo, controlável ou incontrolável). As pré-teses aparecem, mas o sistema da saúde continuará operando do modo como opera, em outros termos: vai operar com os recursos financeiros disponíveis, esperando que alguém vá provocar um processo de reforma ou transformação, imaginar uma possível reforma, depois uma reforma (ou não) dos reformadores.

Enfim, sistema da saúde ou da medicina? Para Luhmann, interessou somente esclarecer qual é a função da medicina e, por isso, tratou somente do sistema médico. A medicina cura as doenças, mas não produz saúde no seu sentido pleno, porque esta não existe!?É necessário considerar sempre os códigos binários (doença/saúde, direito/não direito, etc.) que não indicam necessariamente a situação real, mas indicam comunicação, por exemplo: quando um juiz decide em favor de uma das partes, não significa necessariamente que a outra carece de direito, já que cabe ao juiz tomar uma decisão que demarca no sentido positivo ou negativo a própria decisão. Do mesmo modo, quando um profissional da saúde diz que alguém não tem uma doença, não afirma que tal pessoa é completamente sã; diz somente que não encontra motivos para intervir e, assim, marca a sua decisão. Neste sentido, o valor do código binário que tem cognitividade é o da doença, já que o indivíduo ativa o sistema quando privado de saúde.

\section{CONCLUSÃO}

A sociologia das Constituições nasce a partir da reformulação dos conceitos de Luhmann. A Constituição é observada como uma "invenção" que possibilita a "relação" entre direito e política no contexto da sociedade moderna. Ela é, ainda, a limitação entre os sistemas da política e do direito.

Compreender a Constituição como aquisição evolutiva, na perspectiva luhmanniana, serve como ponto de partida para reflexão da Constituição para além 
dos valores. A sociologia da Constituição não pode e nem deve ser ideológica. A sua lógica de operação não pode ser semelhante ou igual à concepção da Ciência Política ou do Direito. A Sociologia da Constituição nos permite observar que a Constituição se autolegitima e confere limites ao direito e à política.

A saúde apresenta-se como valor simbólico que foi constitucionalizado, no entanto, é preciso sair do plano meramente simbólico e passarmos para o real. O problema é como e onde estabelecer os critérios para que o sistema da saúde e do direito possam operar, ou melhor, como este direito possa ser decidido na estrutura do sistema da saúde.

Considerando este ponto, concluímos que hoje, nos enquadramos em uma sociedade complexa, e que o sociólogo, portanto, se depara com paradoxos, possibilitando diversos meios a serem analisados, discutidos, revistos para que assim a efetividade consiga existir.

\section{REFERÊNCIAS}

CAMACHO, Emilio. Golpe parlamentario em Paraguay: una aproximación jurídico. Assunção: Frente Guasu, 2012.p. 27.

CORSI, Giancarlo. Lo Scopo della Pedagogia Reformista: Eccellenza senza Discriminazioni. Universidatà Bielefeld: 1996. Tese de Doutorado. Universität Bielefeld: 1996.

KANT, Immanuel. Doutrina do Direito. Tradução de Edson Bini. 3. ed. São Paulo: Ícone, 2005.

LUHMANN, Niklas. Der Medizinische Code. In: Soziologische Aufklärung 5: Konstruktivistische Perspektiven, Westdeutscher Verlag, Opladen: 1990, 183-195; Tradução em italiano: LUHMANN, Niklas. Il codice della medicina. In: Salute e malattia nella teoria dei sistemi,: Milano: FrancoAngeli, 2015.

LUHMANN, Niklas. Introdución a la teoría de sistemas. México (DF): Antrhopos, 1996a.

LUHMANN, Niklas Sociologia del rischio. Tradução: Bruno Mondadori. Milano, 1996 b.

LUHMANN, Niklas; DE GIORGI, Raffaele. Teoria della società. Milano: Franco Angeli, 1996c.

LUHMANN, Niklas. Inflazione di pretese nel sistema delle malattie: una presa di posizione dal punto di vista della teoria della società. In: CORSI, Giancarlo. Salute e 
malattia nella teoria dei sistemi. Milano: FrancoAngeli, 2015.

NEVES, Marcelo. A constitucionalização simbólica. São Paulo: Martins Fontes, 2007. p 74-75.

RESTA, Eligio. Percursos da Identidade. Uma Abordagem Jusfilosófica. Tradução de Doglas Cesar Lucas. Ijuí: Editora Unijuí, 2014.

SCHWARTZ, Germano; PRIBÁN, Jiri; ROCHA, Leonel Severo. Sociologia Sistemico Autopoietica das Constituições. Porto Alegre: Livraria do Advogado, 2015. 